\title{
PRIMJER GODIŠNJEG IZVEDBENOG KURIKULUMA ZA DRUGI RAZRED OŠ PEHLIN
}

\author{
Biljana Trajkovski ${ }^{1}$ \\ 1 \\ Učiteljski fakultet Sveučilišta u Rijeci
}

\begin{abstract}
Sažetak
Na uzorku od 20 ispitanika starih 8 godina \pm 6 mjeseci (10 dječaka i 10 djevojčica), OŠ Pehlin, bio je primijenjen sustav baterije mjernih instrumenata od ukupno 12 varijabli (5 morfoloških, 6 motoričkih i jedna funkcionalna), s ciljem utvrđivanja razine antropoloških obilježja radi optimalnog programiranja, odnosno optimalnog prilagođavanja zadataka, sadržaja, volumena opterećenja i metoda rada autentičnim potrebama mjerenih učenika.

Podatci su dobiveni primjenom osnovnih statističkih parametara (AS, SD) skupina po spolu i uspoređeni su s vrijednostima za taj uzrast u Republici Hrvatskoj (Findak i suradnici, 1996). Temeljem analize izračunatih rezultata u morfološkim varijablama može se zaključiti da su i djevojčice i dječaci skladno građeni i da nemaju izrazitije količine masti u tijelu. U prostoru motoričkih sposobnosti analiza dobivenih rezultata ukazuje kod djevojčica na nešto nižu razinu statičke snage ruku i ramenog pojasa (MIV) i eksplozivne snage nogu (MSD), dok je kod dječaka niža razina sposobnosti izražena u testu eksplozivne snage nogu (MSD). Učenici i učenice su dobrih funkcionalnih sposobnosti.
\end{abstract}

Ključne riječi: antropološka obilježja, učenici i učenice, programiranje

\section{Uvod, problem i cilj rada}

Poznato je da je tjelesna aktivnost preduvjet za optimalan rast i razvoj čovjeka (Canadian Paediatric Society, 2002) i da ima velik utjecaj na zdravlje. Motorički aktivna djeca, prema velikom broju istraživanja (Campbell, 2006 i Parfitt, 2005) imaju bolje i kvalitetnije razvijena i izražena kognitivna, konativna, socioemocionalna i ostala antropološka obilježja za razliku od djece koja žive sedentarnim načinom života i kod koje se češće i u kasnijoj životnoj dobi pojavljuju različite aberacije i oboljenja (adipozitet, dijabetes, osteoporoza, kardiovaskularna oboljenja itd.). Pozitivan utjecaj tjelesne aktivnosti na zdravlje očituje se u pravilnom rastu i razvoju svih karakteristika i sposobnosti djece, u usvajanju i razvijanju raznovrsnih motoričkih (biotičkih, socijalnih i kinezioloških) znanja i vještina potrebnih u svakodnevnom životu.

Govoreći o tjelesnom razvoju, djetinjstvo je razdoblje u kojemu je tjelesni razvoj najočitiji te se osoba tada najviše mijenja i razvija. Važno je naglasiti kako nemaju sva djeca istu razinu tjelesnog razvitka s obzirom na dob, nemaju iste kompetencije za tjelesne aktivnosti te imaju različite interese. Danas smo svjedoci izrazitih promjena tjelesnih mjera kod mladih, a najuočljivije su u razvojnim promjenama (Kondrič i sur., 2002). Ipak, zadatak učitelja je dobro upoznati svakog svojeg učenika, upoznati okolinu u kojoj on odrasta te upoznati njegove interese.

Problem ovog rada je utvrđivanje stanja antropoloških obilježja učenika drugog razreda osnovne škole Pehlin kao osnove za kvalitetno programiranje kinezioloških aktivnosti na osnovi usporedbe aktualnog stanja s postojećim normama antropoloških obilježja u Republici Hrvatskoj (Findak i suradnici, 1996), koje su još uvijek valjane i aktualne jer svjedoče upravo drastičnom opadanje antropoloških obilježja naše djece. 
Cilj ovog rada bio je utvrditi razinu određenih motoričkih i funkcionalnih sposobnosti i morfoloških karakteristika učenika drugog razreda OŠ Pehlin u cilju kvalitetnog, odnosno optimalnog odabira kinezioloških sadržaja te izrade izvedbenog godišnjeg kurikuluma.

\section{Metode rada}

Na uzorku od 10 dječaka i 10 djevojčica u dobi 8 godina \pm 6 mjeseci bio je primijenjen sustav od ukupno 12 varijabli, od toga 6 motoričkih, jedne funkcionalne i 5 morfoloških varijabli.

Za procjenu morfoloških karakteristika bile su primijenjene sljedeće varijable: visina tijela (VIS), težina tijela (TEZ), opseg podlaktice (AOP) i kožni nabor nadlaktice (ANN) ( Findak i sur, 1996), te je iz omjera tjelesne visine i težine izračunat indeks tjelesne mase (BMI), Colle i sur., 2000).

Za procjenu motoričkih sposobnosti bio je primijenjen sustav od 6 varijabli: jedna (1) varijabla za procjenu koordinacije - poligon natraške (MPN), tri (3) varijable za procjenu snage- skok u dalj s mjesta (MSD), izdržaj u visu zgibom (MIV) i podizanje trupa (MPT), jedna (1) varijabla za procjenu fleksibilnosti - pretklon u sijedu raznožno (MPR), jedna (1) varijabla za brzinu alternativnih pokreta - taping rukom (MPT) (Findak i sur., 1996).

Za procjenu funkcionalnih sposobnosti bio je primijenjen sustav od 1 varijable: Trčanje 3 minute (F3).

Podaci su prikupljeni inicijalnim provjeravanjem u školskoj godini 2019./2020.

Rezultati mjerenja obrađeni su standardnim statističkim postupkom za dobivanje osnovnih statističkih pokazatelja. Izračunate su aritmetičke sredine mjerenih varijabli (AS), standardne devijacije (SD), prosjeci RH (RH), standardne devijacije RH (SDRH) i Z-vrijednosti za određivanje prioriteta.

\section{Analiza antropoloških obilježja}

Rezultati dobiveni mjerenjem prikazani su u tablici 1 za učenice i tablici 2 za učenike

Tablica 1. Rezultati mjerenja antropoloških obilježja učenica

\begin{tabular}{|c|l|l|l|l|l|l|l|l|l|l|l|l|}
\hline OŠ Pehlin & \multicolumn{10}{|c|}{ 2. razred } \\
\hline Učenice & \multicolumn{10}{|c|}{ MARIJABLE } \\
\hline & ATT & ATV & BMI & AOP & ANN & MTR & MSD & MPN & MPT & MPR & MIV & F3 \\
\hline $\mathbf{l}$. & 131,5 & 29 & 16,77 & 17,5 & 13 & 20 & 137 & 20,1 & 23 & 57 & 18 & 520 \\
\hline $\mathbf{2}$ & 129 & 25 & 15,02 & 16 & 11 & 21 & 140 & 21,2 & 9 & 55 & 3 & 558 \\
\hline $\mathbf{3 .}$ & 144 & 42 & 20,25 & 21 & 16 & 17 & 74 & 25,3 & 23 & 43 & 0 & 435 \\
\hline $\mathbf{4}$. & 123 & 25,5 & 16,86 & 17,5 & 8 & 23 & 117 & 16,1 & 35 & 48 & 22 & 520 \\
\hline $\mathbf{5 .}$ & 131 & 31 & 18,06 & 18,5 & 12 & 26 & 133 & 13,7 & 34 & 60 & 25 & 562 \\
\hline $\mathbf{6 .}$ & 142 & 35 & 17,36 & 20 & 13 & 15 & 148 & 27,2 & 23 & 49 & 36 & 585 \\
\hline $\mathbf{7}$. & 115 & 25 & 18,90 & 18 & 13 & 16 & 110 & 22,5 & 25 & 45 & 4 & 473 \\
\hline $\mathbf{8 .}$ & 138 & 25 & 13,13 & 18 & 8 & 20 & 78 & 27,2 & 23 & 50 & 8 & 462 \\
\hline $\mathbf{9}$. & 134 & 26 & 14,48 & 18 & 9 & 17 & 100 & 28,6 & 29 & 48 & 6 & 428 \\
\hline $\mathbf{1 0 .}$ & 131 & 24,5 & 14,28 & 18 & 11 & 18 & 140 & 26,4 & 23 & 32 & 16 & 518 \\
\hline AS & 131,85 & 28,8 & 16,51 & 18,25 & 11,4 & 19,3 & 118,8 & 22,83 & 24,7 & 48,7 & 13,8 & 506,1 \\
\hline ASRH & 128,5 & 26,2 & 18,3 & 17,8 & 10,49 & 16,02 & 129,34 & 30,0 & 22,16 & 41,38 & 17,64 & 472,1 \\
\hline SDRH & 5,59 & 5,31 & & 1,47 & 3,43 & 1,47 & 17,72 & 8,35 & 7,09 & 8,06 & 12,64 & 76,25 \\
\hline Z & 0,6 & 0,5 & & 0,31 & 0,27 & 2,23 & $-0,6$ & 0,86 & 0,36 & 0,91 & $-0,30$ & 0,45 \\
\hline PRIORITETI & & & & & & 7 & 1 & 5 & 3 & 6 & 2 & 4 \\
\hline
\end{tabular}


Tablica 2. Rezultati mjerenja antropoloških obilježja učenika

\begin{tabular}{|c|c|c|c|c|c|c|c|c|c|c|c|c|}
\hline \multicolumn{2}{|l|}{ OŠ Pehlin } & \multicolumn{11}{|c|}{ 2. razred } \\
\hline \multirow[t]{2}{*}{ Učenici } & \multicolumn{12}{|c|}{ VARIJABLE } \\
\hline & ATT & ATV & BMI & AOP & ANN & MTR & MSD & MPN & MPT & MPR & MIV & F3 \\
\hline 1. & 122 & 28 & 18,8 & 16 & 13 & 16 & 123 & 19,8 & 25 & 44 & 90 & 640 \\
\hline 2. & 132 & 30 & 17,2 & 19 & 11 & 25 & 150 & 23 & 29 & 42 & 26 & 550 \\
\hline 3. & 127 & 27 & 16,7 & 17 & 4 & 20 & 133 & 15 & 37 & 55 & 25 & 630 \\
\hline 4. & 147 & 33 & 15,3 & 18 & 9 & 21 & 126 & 14,3 & 35 & 53 & 24 & 630 \\
\hline 5. & 140 & 26,5 & 13,5 & 19,5 & 11 & 25 & 105 & 22,2 & 31 & 28 & 10 & 450 \\
\hline 6. & 141 & 30 & 15,1 & 20 & 13 & 15 & 144 & 26,7 & 32 & 46 & 25 & 570 \\
\hline 7. & 132 & 36 & 20,7 & 22 & 15 & 12 & 128 & 24,5 & 26 & 43 & 21 & 450 \\
\hline 8. & 138 & 27 & 14,2 & 18 & 8 & 18 & 120 & 21,2 & 29 & 39 & 24 & 573 \\
\hline 9. & 141 & 27 & 13,6 & 18 & 7 & 20 & 120 & 23,5 & 28 & 38 & 31 & 459 \\
\hline 10. & 130 & 24 & 14,2 & 17 & 10 & 21 & 91 & 19,6 & 25 & 42 & 3 & 600 \\
\hline AS & 135 & 28,9 & 15,93 & 18,45 & 10,1 & 19,3 & 124 & 20,96 & 29,7 & 43 & 28,9 & 555,2 \\
\hline ASRH & 130,15 & 27,2 & 18,4 & 18,28 & 8,85 & 16,28 & 137,24 & 25,24 & 23,73 & 35,18 & 21,92 & 500,54 \\
\hline SDRH & 5,71 & 5,26 & & 1,51 & 3,46 & 2,45 & 20,73 & 7,95 & 6,38 & 8,27 & 13,96 & 68,39 \\
\hline $\mathbf{Z}$ & 0,85 & 0,31 & & 0,11 & 0,36 & 1,23 & $-0,64$ & 0,54 & 0,93 & 0,95 & 0,5 & 0,79 \\
\hline PRIORITETI & & & & & & 7 & 1 & 3 & 5 & 6 & 2 & 4 \\
\hline
\end{tabular}

Temeljem analize izračunatih rezultata u morfološkim varijablama može se zaključiti da su i djevojčice i dječaci skladno građeni i da nemaju izrazitije količine masti u tijelu. U prostoru motoričkih sposobnosti analiza dobivenih rezultata ukazuje kod djevojčica na nešto nižu razinu statičke snage ruku i ramenog pojasa (MIV) i eksplozivne snage nogu (MSD), dok je kod dječaka niža razina sposobnosti izražena u testu eksplozivne snage nogu (MSD). Učenici i učenice su dobrih funkcionalnih sposobnosti.

\section{Godišnji izvedbeni kurikulum za drugi razred}

U drugom razredu osnovne škole predviđeno je ostvarenje osam ishoda kroz četiri domene (Kurikulum za nastavni predmet Tjelesne i zdravstvene kulture, 2016) u ukupnom fondu od 105 sati godišnje (3 puta tjedno).

Polazeći od ishoda i poštujući inicijalno stanje antropološkog statusa učenika napravljen je godišnji izvedbeni kurikulum za drugi razred OŠ Pehlin.

Domena A : Kineziološka, teorijska i motorička znanja (A.2.1. Izvodi prirodne načine gibanja i mijenja položaj tijela u prostoru; A.2.2. Provodi elementarne igre).

\begin{tabular}{|c|c|c|}
\hline MJESEC & $\begin{array}{l}\text { A.2.1. (80 SATI) } \\
\end{array}$ & A.2.2. (80 SATI) \\
\hline RUJAN & $\begin{array}{l}\text { Trčanje uz promjenu smjera kretanja; Kombiniranje hodanja i } \\
\text { trčanja na zadani znak Sunožno preskakivanje vijače; Skok u } \\
\text { dalj; Gađanje lopticom u označenu metu s različitih udaljenosti; } \\
\text { Bacanje i hvatanje košarkaške lopte u paru;,Dodavanje i } \\
\text { hvatanje s obje ruke; Na mjestu dodavanje lopte u paru s obje } \\
\text { ruke;Kolut naprijed; Mješoviti upori u hodanju; Prvi dan jeseni } \\
\text { - elementi plesa "Jesenji listovi"; osnovni oblici kretanja uz } \\
\text { glazbu različitog ritma i tempa. }\end{array}$ & $\begin{array}{l}\text { Štafetna igra "Daj mi pet"; } \\
\text { Elementarna igra "Poplava i } \\
\text { avioni", Košarka - u } \\
\text { parovima dodavanje lopte } \\
\text { odbijanjem lopte od tla; } \\
\text { Nogomet -udarac na vrata s } \\
\text { izmjenom noge }\end{array}$ \\
\hline LISTOPAD & $\begin{array}{l}\text { Trčanje uz promjene pravca kretanja preko prepreka; Slobodno } \\
\text { pretrčavanje prepreka do } 20 \mathrm{~cm} \text { visine; Poskoci na jednoj nozi } \\
\text { iz obruča u obruč; Skok u dalj; Hvatanje s obje ruke na mjestu; } \\
\text { U laganom kretanju voditi loptu, Gađanje loptom u okvir } \\
\text { sanduka; Bacanje lopti u različite smjerove iz mjesta, Povaljka } \\
\text { na leđima iz čučnja do čučnja; Svjetski dan zaštite životinja - } \\
\text { improvizacija koreografije - oponašanje kretanja životinja } \\
\text { "Pačji ples". }\end{array}$ & $\begin{array}{l}\text { Odbojka- iz kretanju } \\
\text { zaustavljanje u odbojkaškom } \\
\text { stavu; } \\
\text { Rukomet - dodavanje i } \\
\text { hvatanje lopte u parovima; } \\
\text { Ekipna igra "Tunel", "Živo }\end{array}$ \\
\hline
\end{tabular}




\begin{tabular}{|c|c|c|}
\hline & & $\begin{array}{l}\text { uže"; Elementarna igra } \\
\text { "Zvijezda" }\end{array}$ \\
\hline STUDENI & $\begin{array}{l}\text { Hodanje po klupi preko označivača prostora ili malih prepreka; } \\
\text { Ciklička kretanja različitim tempom do } 3 \text { minute; Trčanje } \\
\text { unatrag; Sunožni preskoci preko kapica/označivača prostora; } \\
\text { Skok u dalj; Dodavanje lopte nogom; Gađanje lopte u gol iz } \\
\text { mjesta; Dodavanje i hvatanje rukometne lopte u paru;Bacanje i } \\
\text { hvatanje lopte u stojećem stavu; Bočno kotrljanje po tlu u jednu } \\
\text { i drugu stranu; Penjanje na švedski sanduk; Penjanje po kosini } \\
\text { četveronoške }\end{array}$ & $\begin{array}{l}\text { Badminton, } \\
\text { dodavanje i hvatanje lopte; } \\
\text { Rukomet - poigravanje } \\
\text { loptom na mjestu s } \\
\text { dominantnom rukom; } \\
\text { Štafetna igra "Kotrljanje } \\
\text { lopte kroz tunel", Ekipna igra } \\
\text { "Za mnom", "Ribari i ribice" }\end{array}$ \\
\hline PROSINAC & $\begin{array}{l}\text { Brzo hodanje uz promjenu pravca kretanja; Trčanje - niski skip } \\
\text { u kretanju; Sunožni poskoci u kretanju preko niskih prepreka do } \\
20 \mathrm{~cm} \text {; Skok u dalj; Gađanje lopte u okvir sanduka; Vođenje } \\
\text { lopte na mjestu; Bacanje lakših lopti u zid i hvatanje istih; } \\
\text { kretanje u krugu i dodavanje lopte od strane učitelja; Provlačenje } \\
\text { kroz okvir sanduka; Uskakivanje u obruč i provlačenje; Prvi dan } \\
\text { zime - Ritmičko povezivanje jednonožnih i sunožnih skokova; } \\
\text { Oponašanje različitih ljudskih aktivnosti - improvizacija } \\
\text { koreografije) }\end{array}$ & $\begin{array}{l}\text { Elementarna igra "Kipovi", } \\
\text { "Lovac u šumi", Štafetna } \\
\text { igra "Do čunja i nazad", } \\
\text { Nogomet - vođenje lopte } \\
\text { unutarnjom stranom stopala, } \\
\text { dodavanje lopte u paru na } \\
\text { mjestu; Rukomet - } \\
\text { dodavanje s obje ruke } \\
\text { raskorakom }\end{array}$ \\
\hline SIJEČANJ & $\begin{array}{l}\text { Trčanje uz promjenu smjera kretanja; Hodanje po klupi preko } \\
\text { označivača prostora ili malih prepreka; Poligoni hodanja i } \\
\text { trčanja; Bočni sunožni preskoci preko klupica; Skok u dalj; } \\
\text { Bacanje lopti različitih veličina u različitim smjerovima; } \\
\text { Gađanje lopticom u cilj s različitih udaljenosti; } \\
\text { Iz raskoračenog stava u dubokom pretkolu izbaciti loptu u vis; } \\
\text { Kolut natrag niz kosinu; Trčanje u ritmu uz udaraljke i glazbu }\end{array}$ & $\begin{array}{l}\text { Ekipna igra "Grudanje", } \\
\text { Štafetna igra "Kotrljanje } \\
\text { lopte kroz tunel"; Ekipne igre } \\
\text { na snijegu; Rukomet - } \\
\text { dodavanje i gađanje na gol } \\
\text { dominantnom rukom }\end{array}$ \\
\hline VELJAČA & $\begin{array}{l}\text { Trčanje - niski skip u kretanju; Kombiniranje hodanja i trčanja } \\
\text { na zadani znak; Trčanje uz promjene pravca kretanja preko } \\
\text { prepreka: preskakivanje vijače u paru; Sunožni odraz s daske i } \\
\text { naskok na povišenje; Penjanje na švedske ljestve, silaženje po } \\
\text { kosoj klupi i suprotno; Izbacivanje lopte s obje ruke iznad glave } \\
\text { u dalj; Bacanje medicinke na različite načine; Vođenje } \\
\text { odbojkaške lopte rukom na mjestu; Stoj penjanjem uz okomitu } \\
\text { plohu }\end{array}$ & $\begin{array}{l}\text { Košarka - gađanje loptom u } \\
\text { okvir sanduka; Rukomet - } \\
\text { poigravanje loptom desnom i } \\
\text { lijevom rukom; Nogomet - } \\
\text { dodavanje lopte s } \\
\text { unutarnjom stranom stopala; } \\
\text { Ekipna igra "Provlačenje } \\
\text { kroz kanal" }\end{array}$ \\
\hline OŽUJAK & $\begin{array}{l}\text { Trčanje s visokim podizanjem koljena (visoki skip) preko } \\
\text { kapica; Brzo hodanje uz promjenu pravca kretanja; Naskok na } \\
\text { švedski sanduk (visina } 40 \mathrm{~cm} \text { ) i sunožni saskok; Skok u dalj iz } \\
\text { zaleta; Bacanje rukometne lopte u zid i hvatanje; Gađanje } \\
\text { lopticom u cilj s različitih udaljenosti; Dodavanje i hvatanje s } \\
\text { obje ruke u parovima; Kolut naprijed; Jednostavni plesni koraci } \\
\text { aerobike uz vodstvo učitelja; Jednostavni dječji ples "Ludi } \\
\text { zemljotres" }\end{array}$ & $\begin{array}{l}\text { Elementarna igra "Slonovski } \\
\text { nogomet",Nogomet } \\
\text { vođenje lopte u kretanju; } \\
\text { Rukomet - izbacivanje lopte } \\
\text { zamahom, dodavanje i } \\
\text { hvatanje lopte na različite } \\
\text { načine }\end{array}$ \\
\hline TRAVANJ & $\begin{array}{l}\text { Trčanje unatrag, Brzo trčanje do } 30 \text { m; Hodanje po klupi preko } \\
\text { označivača prostora ili malih prepreka; Bočno trčanje; Naskok } \\
\text { na švedski sanduk; Skok u dalj; U kretanju dodavanje lopte u } \\
\text { paru; Gađanje lopte u okvir sanduka; Dodavanje lopte nogom u } \\
\text { parovima; Hvatanje i dodavanje košarkaške lopte u različitim } \\
\text { smjerovima; Kolut natrag niz kosinu; Kolut naprijed kroz obruč; } \\
\text { Narodni ples - u parovima; Ritmičko povezivanje jednonožnih } \\
\text { i sunožnih skokova; Puzanje i provlačenje na različite načine }\end{array}$ & $\begin{array}{l}\text { Košarka - dodavanje i } \\
\text { hvatanje u kretanju; Odbojka } \\
\text { - odbojkaški stav; Štafetna } \\
\text { igra "Hvatanje loptom", } \\
\text { Ekipna igra "Ribari i ribice; } \\
\text { Elementarna igra "Kipovi", } \\
\text { "Hugo" }\end{array}$ \\
\hline SVIBANJ & $\begin{array}{l}\text { Slobodno pretrčavanje prepreka do } 20 \mathrm{~cm} \text { visine; Ciklička } \\
\text { kretanja različitim tempom do } 3 \text { minute; Skok u dalj iz ravnog } \\
\text { zaleta; preskakivanje duge vijače u parovima; Bacanje lopte u } \\
\text { vis s obje ruke i hvatanje s obje ruke; Gađanje lopticom u cilj s } \\
\text { različitih udaljenosti; Plesne strukture uz ritam glazbe; } \\
\text { Suvremeni ples - Bečki valcer; Penjanje, puzanje i provlačenje } \\
\text { povezano (uz korištenje umjetnih i prirodnih prepreka)) }\end{array}$ & $\begin{array}{l}\text { Plivanje - držanje za rub } \\
\text { bazena i udaranje nogama - } \\
\text { projekt PGŽ "Rijeka pliva"; } \\
\text { Štafetna igra "Tko bolje } \\
\text { gađa"; Ekipna igra u prirodi } \\
\text { "Povlačenje konopa" }\end{array}$ \\
\hline
\end{tabular}




\begin{tabular}{|l|l|l|}
\hline LIPANJ & $\begin{array}{l}\text { Trčanje između čunjića; Hodanje po gredi na prstima; Poligoni } \\
\text { hodanja i trčanja; Naskok na povišenje uz saskok u čučnju, }\end{array}$ & $\begin{array}{l}\text { Plivanje - držanje za rub } \\
\text { bazena i udaranje nogama - } \\
\text { Jednonožno i sunožno skakanje po označenim mjestima; U } \\
\text { projekt PGŽ "Rijeka pliva"; } \\
\text { kretanju dodavanje lopte u paru; Dodavanje i hvatanje s obje } \\
\text { ruke u paru; Gađanje lopticom u okvir sanduk; Naizmjenično } \\
\text { upiranje u paru "kariola"; Osnovni oblici kretanja uz glazbu } \\
\begin{array}{l}\text { različitog ritma i tempa } \\
\text { gađa"; Ekipna igra u prirodi } \\
\text { "Povlačenje konopa" }\end{array}\end{array}$ \\
\hline
\end{tabular}

Domena B : Morfološka obilježja, motoričke i funkcionalne sposobnosti (B.2.1. Sudjeluje u provjeravanju antropološkog statusa i pravilnoga tjelesnog držanja).

\begin{tabular}{|l|c|}
\hline MJESEC & B.2.1. (5 SATI) \\
\hline RUJAN & INICIJALNO PROVJERAVANJE \\
& Mjerenje antropoloških obilježja \\
& (ATT,ATV,BMI,AOP,ANN,MTR,MPN,MIV,MSD,MPT,MPR,F3) \\
& ZAVRŠNO PROVJERAVANJE \\
& Mjerenje antropoloških obilježja \\
& (ATT,ATV,BMI,AOP,ANN,MTR,MPN,MIV,MSD,MPT,MPR,F3) \\
\hline
\end{tabular}

Domena C : Motorička postignuća (C.2.1. Uključen je u praćenje osobnih motoričkih postignuća).

\begin{tabular}{|l|l|}
\hline MJESEC & \multicolumn{1}{|c|}{ C.2.1. (15 SATI) } \\
\hline LISTOPAD & Preskakivanje kratke vijače sunožno na mjestu - 15 sekundi \\
\hline STUDENI & Cikličko kretanje s promjenom tempa do 2 minute \\
\hline PROSINAC & Skok u dalj iz mjesta \\
\hline SIJEČANJ & Vođenje lopte nogom i gađanje na gol (N) \\
\hline OŽUJAK & Sunožni poskoci - 20 metara \\
\hline TRAVANJ & Brzo trčanje iz visokog starta -20 metara \\
\hline SVIBANJ & Skok u dalj iz zaleta \\
\hline
\end{tabular}

Domena D : Zdravstveni i odgojni učinci tjelesnog vježbanja (D.2.1. Prepoznaje i primjenjuje postupke za održavanje higijene pri tjelesnoj aktivnosti te se brine o opremi za tjelesno vježbanje; D.2.2. Usvaja mogućnosti tjelesnog vježbanja na otvorenim i zatvorenim sportskim vježbalištima; D.2.3. Surađuje u elementarnim igrama i prihvaća pravila igara; D.2.4. Aktivno sudjeluje u elementarnim igrama koje razvijaju samopoštovanje, samopouzdanje i ustrajnost.

\begin{tabular}{|l|l|}
\hline SVAKI NASTAVNI SAT (105 SATI) \\
\hline D.2.1. & $\begin{array}{l}\text { razvija svijest o potrebi provođenja tjelesnog vježbanja } \\
\text { redovito provodi osobnu higijenu nakon tjelesnog vježbanja } \\
\text { uočava važnost nošenja primjerene odjeće i obuće za tjelesno vježbanje } \\
\text { prati svoje higijenske postupke } \\
\text { ispunjava tablicu donošenja opreme }\end{array}$ \\
\hline D.2.2. & primjenjuje kineziološke motoričke aktivnosti na otvorenim i zatvoreni sportskim vježbalištima \\
\hline D.2.3. & $\begin{array}{l}\text { razvija timski duh prilikom ekipnih i sportskih igara } \\
\text { prihvaća pravila igara } \\
\text { surađuje s ostalim učenicima u igrama }\end{array}$ \\
\hline
\end{tabular}




\begin{tabular}{|l|l|}
\hline & $\begin{array}{l}\text { osvješćuje važnost sudjelovanja svih učenika kako bi se ostvario uspjeh } \\
\text { pridonosi uspjehu cijele skupine } \\
\text { rado sudjeluje u motoričkim igrama } \\
\text { nabraja pravila igre i poštuje ih } \\
\text { slijedi upute učitelja kako se ponašati u igri }\end{array}$ \\
\hline D.2.4. & $\begin{array}{l}\text { izvodi elementarne igre koje razvijaju samopoštovanje i samopouzdanje } \\
\text { uočava da ustrajnošću može postići ciljeve } \\
\text { pridonosi stvaranju pozitivnog ozračja tijekom elementarnih igara } \\
\text { rado izvodi kineziološke aktivnosti }\end{array}$ \\
\hline
\end{tabular}

\section{Zaključak}

Školsko životno razdoblje je povoljno vrijeme za stimuliranje razvoja svih antropoloških obilježja te povećanje optimalnog dosega motoričkih znanja, ponajviše biotičkih, a zatim kinezioloških. Poznato je da se u tom razdoblju propuštene mogućnosti na usvajanje motoričkih znanja i razvoj motoričkih i funkcionalnih sposobnosti ne mogu u potrebitoj mjeri nadoknaditi u kasnijim životnim razdobljima ma koliko intenzivirali razvojne poticaje, kako u obitelji, tako i u školi. Samo uz adekvatne i dostatne podražaje i poticaje djeca mogu razvijati svoja antropološka obilježja kako bi odgovorila suvremenim izazovima života.

\section{Literatura}

1. Cole, T., J., Belizzi, M.C., Flegal, K.M., Dietz, W.H. (2000). Establishing a standard definition for child overweight and obesity worldwide: International survey. BMJ Vol. 320 (1240-1243).

2. Campbell SK (2006). The child development of functional muvement. Phisical Therapy for children. : 33-76.

3. Canadian Paediatric Society (2002). Healthy active living for children and youth. Pediatric Child Health. 7: 339-345.

4. Findak, V., Metikoš, D., Mrakovi, M, Neljak, B. (1996). Primijenjena kineziologija u školstvu-NORME. Zagreb: Hrvatski pedagoško-književni zbor, Fakultet za fizičku kulturu Sveučilišta u Zagrebu.

5. Kondrič, M., Mišigoj-Duraković, M. i Metikoš, D. (2002). A contribution to understanding relations between morphological and motor characteristics in 7- and 9year-old boys . Kinesiology, 34. (1.), 5-15.

6. Kurikulum za nastavni predmet Tjelesne i zdravstvene kulture (2016).

7. Nastavni plan i program za osnovnu školu (2006). Ministarstvo znanosti, obrazovanja i športa. Zagreb.

8. Parfitt G, Eston RG. ( 2005). The relationship between children: looking beyond fitness and fatness to attention, affilation, and affect. Archives of Pediatrics and adolescents medicine. 159: 46-50. 